\title{
Induction by left ventricular overload and left ventricular failure of the human Jumonji gene (JARID2) encoding a protein that regulates transcription and reexpression of a protective fetal program
}

\author{
Esta Bovill, MBBS, ${ }^{\text {a }}$ Stephen Westaby, MS PhD, ${ }^{\text {b }}$ Shiney Reji, $\mathrm{PhD}^{\mathrm{a}}$ Rana Sayeed, MD, ${ }^{\mathrm{b}}$ Alastair Crisp, MA, ${ }^{\mathrm{c}}$ and \\ Tony Shaw, $\mathrm{PhD}^{\mathrm{a}}$
}

From the Department of Medicine, University College London, London, $\mathrm{UK}^{\mathrm{a}}$; John Radcliffe Hospital, Oxford, $\mathrm{UK}^{\mathrm{b}}$; and the Department of Physiology, Anatomy \& Genetics, University of Oxford, Oxford, $\mathrm{UK}^{\mathrm{c}}$.

Supported by research grants from the British Heart Foundation (E.B., S.W., and T.S.), the Artificial Heart Fund (S.W. and T.S.), and the Oak Foundation (T.S.).

Received for publication Aug 19, 2007; revisions received Jan 23, 2008; accepted for publication Feb 15, 2008.

Address for reprints: Esta Bovill, MBBS, c/o Oxford Heart Centre, John Radcliffe Hospital, Headley Way, Headington, Oxford OX3 9DU, UK (E-mail: ebovill@doctors.net.uk).

J Thorac Cardiovasc Surg 2008;136:709-16 0022-5223/\$34.00

Copyright (C) 2008 by The American Association for Thoracic Surgery

doi:10.1016/j.jtcvs.2008.02.020
Objective: We identified changes in Jumonji (JARID2) expression in failing human hearts and determined its effects on expressions of atrial natriuretic factor $(A N F)$, myosin light chain $2 \mathrm{a}(M L C 2 A)$, and $\alpha$ myosin heavy chain $(M H C A)$, genes associated with both human heart failure and the fetal gene program.

Methods: Left ventricular outflow tract cardiac biopsy samples were taken from 31 patients with aortic valvular stenosis. Hearts were grouped according to left ventricular size and function: nonfailing hearts (undilated with good function) and failing hearts (dilated with poor function). Protein levels were determined by Western blotting, and messenger RNA transcript levels by ratiometric reverse transcriptase-polymerase chain reaction. Luciferase assays in HL-2 cells were used to assess effects of Jarid 2 on Anf, Mlc2a, and Mhca transcriptions. Chromatin immunoprecipitation was used to detect interaction of JARID2 with specific target-gene promoters.

Results: JARID2 and MHCA expressions were reduced in failing hearts, whereas $M L C 2 A$ and $A N F$ were increased. In HL-2 cell culture, Jarid 2 suppressed Anf and $M l c 2 a$ but enhanced Mhca. Jarid 2 expression was reduced by cyclic mechanical stress, with concomitant increased Anf and Mlc2a and decreased Mhca expressions, reproducing the expression profile found in decompensated human pressure overload.

Conclusion: Jumonji expression is reduced by mechanical stress in human heart failure from aortic stenosis. JARID2 regulates ANF, MLC2A, and MHCA transcription and contributes to reexpression of the fetal gene program in decompensated aortic stenosis. JARID2 appears important in transcriptional regulation of fetal genes and may emerge as a diagnostic marker for left ventricular decompensation in aortic stenosis.

$\mathrm{T}$ The initial response of the heart to hemodynamic overload is cardiac hypertrophy. When overload continues, however, the adaptive hypertrophic changes become deleterious, with progression to decompensated heart failure. ${ }^{1}$ Heart failure is accompanied by structural and physiologic changes that include myocyte hypertrophy, interstitial fibrosis, and altered contractile function. ${ }^{2}$ The phenotypic changes are mediated by the altered expression of particular classes of genes. These include genes encoding contractile proteins and proteins involved in calcium regulation and excitation-contraction coupling, together with reexpression of the fetal gene program. ${ }^{3}$ This involves the ventricular reexpression of fetal and neonatal isoforms of contractile and other proteins, such as atrial natriuretic factor (ANF). These findings have been reported both in heart failure models ${ }^{3,4}$ and in patients with heart failure. ${ }^{5-7}$. Within the human myocyte contractile apparatus, $\alpha$ myosin heavy chain $(\alpha-\mathrm{MHC})$ is the predominant myosin heavy chain isoform expressed in human ventricular myocardium, but messenger RNA (mRNA) expression of the gene for $\alpha$-MHC, MHCA, is greatly reduced in failing hearts. ${ }^{8,9}$. There are also changes in expressions of genes for myosin light chain 2 (MLC-2) in both human heart failure and animal models 


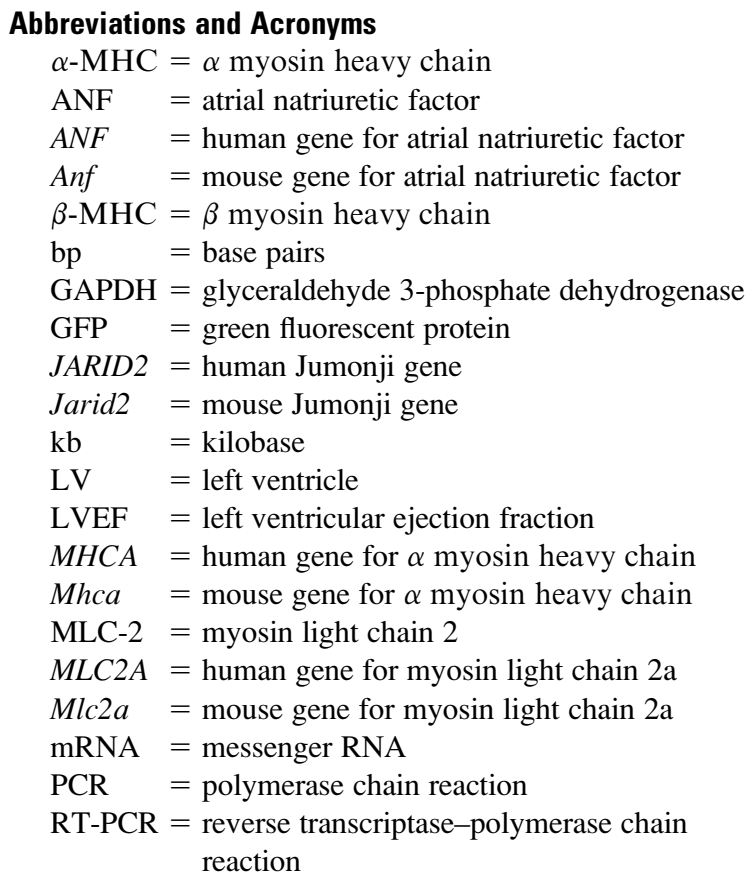

of the disease. ${ }^{10}$ Although several transcriptional regulators of $A N F$, the gene for MLC-2a (MLC2A), and MHCA expressions have been identified in the hypertrophied and failing heart (eg, GATA4, MEF2, Nkx-2.5), the precise molecular pathways responding to hemodynamic overload and to mechanical stress remain to be defined. ${ }^{11,12}$

The human Jumonji gene (JARID2) encodes a 1234amino acid protein homologous to human retinoblastomabinding protein $2 .{ }^{13}$ JARID2 contains nuclear localization signals and an AT-rich interaction domain for DNA binding similar to other transcription factors, such as dead ringer (DmeAretn) in Drosophila and SWII in yeast, ${ }^{14,15}$ but it does not have a well-defined consensus binding sequence. ${ }^{16,17}$ JARID2 has an exclusively nuclear distribution and has recently been identified as a transcriptional regulator of ANF, ${ }^{16} \alpha$-MHC, ${ }^{18}$ and cyclin D1. ${ }^{19-21}$

The mouse Jumonji gene (Jarid2) has been identified as an important factor for normal cardiac development in mice ${ }^{22,23} ;$ Jarid2 is expressed in cardiac and vascular tissues in adult mice, especially in the interventricular septum, ventricular free wall, and outflow tract. In Jarid $2^{-/-}$mice, malformations are found in the interventricular septum and outflow tract (ventricular septal defect and double-outlet right ventricle), and the expression patterns of several cardiac-specific genes are disrupted. ${ }^{22,23}$ Ventricular $A N F$ expression normally declines rapidly just before birth, whereas atrial expression is maintained, ${ }^{24}$ but $A N F$ expression remains high in the Jarid $2^{-1-}$ murine ventricle. ${ }^{22}$ Similarly, ventricular $M L C 2 A$ expression falls during normal cardiac chamber development ${ }^{25}$ but persists in Jarid $2^{-1-}$ hearts. There is failure of the normal switching of $\beta$ myosin heavy chain $(\beta$ MHC) to $\alpha$-MHC in the murine ventricle near birth, with higher ventricular $\beta$-MHC levels and reduced MHCA expression in Jarid $2^{-1-}$ mice. $^{22}$

In view of these findings, we considered that JARID2 expression might be altered in patients with valvular heart disease and that JARID2 might contribute to the regulation of $A N F, M L C 2 A$, and $M H C A$. Patients with aortic stenosis manifest a wide spectrum of left ventricular (LV) function, from normal to severely impaired. In this study, our objectives were to elucidate the molecular response of human LV myocardium to increased afterload in aortic stenosis and to explore the diagnostic potential of these changes to influence the timing of cardiac surgery before hypertrophy devolves into dilatation. We elected to investigate several intuitively logical genes that are associated both with an increase in afterload in experimental animals and with altered cell-cycle influence (eg, ventricular septal defects) in gene-knockout mice.

\section{Materials and Methods}

\section{Procurement of Human Myocardial Tissue}

Under a protocol approved by the Oxford Radcliffe Research Ethics Committee and after informed consent, human myocardial biopsy samples were obtained from the LV outflow tract of selected patients undergoing isolated aortic valve replacement for aortic stenosis (ie, with pressure-overload cardiac hypertrophy). The specimens were obtained from the endocardium of the subvalvular region, away from the conduction tissue and in an area accessible by transcatheter endocardial biopsy. Patients with associated coronary artery disease were excluded. All patients underwent preoperative transthoracic echocardiography to determine LV ejection fraction (LVEF) and LV dimensions. ${ }^{26}$ Study patients were selected to fall clearly into one of two groups on the basis of the echocardiographic assessment of LV function. The failing heart group $(\mathrm{n}=$ 15) had reduced LVEF and increased LV dimensions; the nonfailing group $(n=16)$ had preserved LVEF and normal LV dimensions (Table 1).

TABLE 1. Preoperative echocardiographic assessment and New York Heart Association functional class of patients

\begin{tabular}{|c|c|c|c|}
\hline & Nonfailing & Failing & $\begin{array}{c}\text { Reference } \\
\text { range }\end{array}$ \\
\hline No. of patients & 16 & 15 & \\
\hline Age (y) & $61.6 \pm 15.2$ & $59.7 \pm 18.7$ & \\
\hline $\begin{array}{l}\text { LV end-diastolic } \\
\text { diameter }(\mathrm{cm})\end{array}$ & $4.77 \pm 0.49$ & $6.44 \pm 0.53^{*}$ & $3.5-5.6$ \\
\hline $\begin{array}{l}\text { LV end-systolic } \\
\text { diameter }(\mathrm{cm})\end{array}$ & $2.84 \pm .37$ & $4.3 \pm 0.55^{*}$ & $2.5-4.1$ \\
\hline LV ejection fraction $(\%)$ & $58.33 \pm 5.2$ & $35.4 \pm 4.92^{*}$ & $55-75$ \\
\hline $\begin{array}{l}\text { New York Heart Association } \\
\text { functional class }\end{array}$ & 1.8 & $2.7^{*}$ & \\
\hline
\end{tabular}

Values are mean $\pm S D . L V$, Left ventricular. ${ }^{*} P<.05$ versus nonfailing. 


\section{Western Blotting for JARID2 and ANF}

Myocardial biopsy samples were frozen and ground under liquid nitrogen and stored at $-80^{\circ} \mathrm{C}$. Protein was extracted into a urea buffer (9-mol/L urea, 2\% sodium dodecylsulfate, $2 \%$ 3-[(3-cholamidopropyl)dimethylammonio]-1-propanesulfonate, $0.5 \%$ Triton X100 [The Dow Chemical Company, Midland, Mich], 20-mmol/L dithiothreitol, and 50-mmol/L tris(hydroxymethyl)aminomethane hydrochloride, $\mathrm{pH}$ 7.4), and the concentration of each sample was determined by Bradford assay (Sigma-Aldrich Co, St Louis, Mo). Human JARID2 gene product in myocardial protein isolates was detected by Western blotting. Sodium dodecylsulfate-polyacrylamide gels were loaded with $100-\mu \mathrm{g}$ aliquots of protein for electrophoresis and blotting. Blots were probed with a rabbit polyclonal primary antibody raised against a synthetic peptide of human JARID2 (accession NP004964; Eurogentec Ltd, Hythe, UK) that detects a predicted $145-\mathrm{kDa}$ band for JARID2, a mouse anti-human ANF antibody (Abcam plc, Cambridge, UK) was used to detect ANF, and gel loading was confirmed by reprobing blots with a $\beta$-actin antibody (Abcam). Blots were probed with a horseradish peroxidaselabeled secondary antibody (Dako A/S, Glostrup, Denmark) and analyzed by chemiluminescence (Amersham Biosciences Europe $\mathrm{GmbH}$, Freiburg, Germany) on a densitometer (Bio-Rad Laboratories Inc, Hercules, Calif) to allow calculation of the relative intensity of each band with proprietary software.

\section{Ratiometric Reverse Transcriptase-Polymerase Chain Reaction for MHCA and $M L C 2 A$ mRNA Expressions}

Total RNA was extracted from myocardial biopsy samples with the QIAGEN RNeasy extraction protocol (QIAGEN Ltd, Crawley, United Kingdom), and $1 \mu \mathrm{g}$ total RNA was reverse transcribed according to the manufacturer reverse transcriptase-polymerase chain reaction (RT-PCR) protocol with oligodeoxythymidine primers (Promega Corporation, Madison, Wis); PCR primer sequences and conditions are shown in Table 2. A fragment of 272 base pairs (bp) at the $3^{\prime}$ end of human MLC2A (accession M94547) and a 296bp fragment from the $3^{\prime}$ end of human MHCA (accession D00943) were amplified, and the identities of the products were confirmed by sequencing. Amplified sequences were separated by gel electrophoresis and analyzed on a GeneGnome imaging system (Syngene; Synoptics Ltd, Cambridge, UK) to measure band intensity against glyceraldehyde 3-phosphate dehydrogenase (GAPDH) expression within each sample. ${ }^{27}$

\section{Promoter-Luciferase Constructs and Luciferase Assays}

The 2-kilobase $(\mathrm{kb}) M L C 2 A$ promoter was produced by PCR amplification of a described promoter region ${ }^{28}$ from genomic DNA of HEK293 cells and insertion of the amplified sequence into the BamHI and EcoRI sites of pGL3 Basic Vector (Promega). The 5.6-kb MHCA promoter was provided by Dr J. Gulick and Prof J. Robbins (The Cleveland Clinic, Cleveland, Ohio), ${ }^{29}$ and the 3.7-kb ANF promoter-luciferase construct was supplied by Prof M. Nemer (Institut de Recherches Cliniques de Montréal, Montréal, Quebec, Canada). ${ }^{11}$ Luciferase assays were performed by cotransfecting equimolar amounts of each construct and $40 \mathrm{pg}$ of pRL-CMV Vector (Promega_ into HL-2 cells with the Effectene reagent (QIAGEN); vector-only control experiments were performed concurrently. Cell lysates were assayed for Photinus and Renilla luciferase activities after 48 hours with the Promega dualluciferase assay system; Photinus luciferase activity was normalized against Renilla activity to control for variable transfection efficiencies.

\section{Modified Chromatin Immunoprecipitation of jmj- Promoter Complexes}

HL-2 cells were cotransfected with equimolar amounts of promoterluciferase construct and jmj-green fluorescent protein (GFP) ${ }^{22}$ or GFP vector alone, and a modified chromatin immunoprecipitation assay was performed as previously described ${ }^{30}$ after 48 hours. For each precipitation reaction, a third of the lysate was used as a positive control, and total DNA was ethanol precipitated. Another third of the lysate was diluted 10-fold, and protein-DNA complexes were precipitated by an anti-GFP antibody (Upstate Biotechnology, Inc, Lake Placid, NY) and protein A-agarose. The remaining third of the lysate was processed in parallel with an irrelevant (anti-Myc) antibody. PCR amplification of the luciferase gene was performed on the washed immunoprecipitated complexes. ${ }^{30}$

\section{Jarid2 Expression in Stressed HL-2 Cells}

Murine HL-2 cells, derived from HL-1 cells, were kindly donated by Dr William Claycomb (Louisiana State University Medical Center,

TABLE 2. Primer sequences and polymerase chain reaction conditions

\begin{tabular}{|c|c|c|c|c|}
\hline Primer & Primer sequence $\left(5^{\prime}-3^{\prime}\right)$ & Product size (bp) & Annealing temp $\left({ }^{\circ} \mathrm{C}\right)$ & No. of cycles \\
\hline MHCA human $\mathrm{F}$ & CTGGAGGCCGAGCAGAAG & 296 & 58 & 33 \\
\hline MHCA human $\mathrm{R}$ & CTCTTGGCTCGAAGCTTGTT & & & \\
\hline Mhca mouse $\mathrm{F}$ & CAGCTTGTTGACCTGGGACT & 361 & 58 & 33 \\
\hline Mhca mouse $\mathrm{R}$ & AGAGCAGATCGCCCTCAAG & & & \\
\hline MLC2A human $\mathrm{F}$ & GTCTTCCTCACGCTCTTTGG & 272 & 58 & 33 \\
\hline MLC2A human $\mathrm{R}$ & ССTGССССTСАTTССTСТ & & & \\
\hline Mlc2a mouse $\mathrm{F}$ & TGACCTCAGCCTGTCTACTCC & 342 & 58 & 33 \\
\hline Mlc2a mouse $\mathrm{R}$ & AAGTGTTCCGGAGGAAGAGC & & & \\
\hline Mouse Jarid2 F & GATTGCACAAGCAGAAGCAA & 458 & 58 & 33 \\
\hline Mouse Jarid2 R & TTGGTGTGGGTTTGTTGAGA & & & \\
\hline
\end{tabular}

All polymerase chain reactions were performed with Taq polymerase with an initial 1-minute denaturation step at $94^{\circ} \mathrm{C}$, followed by cycles of 30 -second denaturation at $94^{\circ} \mathrm{C}, 30$-second annealing, and 45 -second extension at $72^{\circ} \mathrm{C}$. $b p$, Base pairs. $\mathrm{F}=$ forward primer, $\mathrm{R}=$ reverse primer. 
New Orleans, La) and grown in Claycomb media (JRH Biosciences, Lenexa, Kan) as previously described. ${ }^{31}$ Cells were subcultured into gelatin- and fibronectin-coated FlexerCell plates (Flexcell International Corporation, Hillsborough, NC) for 24 hours, and then confluent layers of cells were subjected to $7.5 \%$ stretch at $60 \mathrm{~Hz}$ for up to 24 hours on a FlexerCell-4000 tension system (Flexcell). Experiments were performed in triplicate on three separate occasions. Cells were harvested by trypsinization and centrifugation, then washed in ice-cold phosphate-buffered saline solution before total RNA extraction with the QIAGEN RNeasy kit or total protein extraction into Radio Immuno Precipitation Assay (RIPA) buffer. RT-PCR was performed on $1-\mu \mathrm{g}$ aliquots of total RNA with the primers and conditions shown in Table 2 to amplify $3^{\prime}$-terminal fragments of murine Jarid2 (458 bp), Mlc2a (342 bp), and Mhca (361 bp). Amplicon identity was confirmed by sequencing. GAPDH RT-PCR was performed on the same samples, and relative target mRNA expressions were calculated as before.

\section{Statistical Analysis}

Data are expressed as a mean \pm SD. Groups were compared with Student $t$ test or analysis of variance as appropriate.

\section{Results}

\section{Jumonji Expression Reduction in Human Heart}

\section{Failure}

JARID2 protein was reduced by $60 \%(P<.005)$ in failing hearts relative to nonfailing hearts (Figure 1, $A$ and $B$ ). Ventricular ANF protein was expressed only in failing hearts (Figure 1, A). MLC2A mRNA was not detectable by RTPCR in nonfailing hearts but was present in failing hearts (Figure $1, A)$. There was a $42 \%$ decrease $(P<.005)$ in MHCA mRNA expression in failing hearts relative to nonfailing hearts (Figure 1, $A$ and $C$ ).

\section{Jumonji Regulation of Anf, Mlc2a, and Mhca}

Expressions in a Dose-Dependent Manner

In murine HL-2 cell cotransfection experiments, Jumonji induced dose-dependent suppression of Anf (Figure 2, A, left columns) and Mlc2a (Figure 2,B) expressions. In contrast, Jumonji enhanced Mhca expression in a dose-dependent manner (Figure 2, C).

\section{Jumonji interaction With Anf, Mlc2a, and Mhca} Promoters in HL-2 cells

With a modified chromatin immunoprecipitation assay, Jarid2-GFP was immunoprecipitated with target promoterluciferase constructs. PCR for luciferase in precipitated protein-DNA complexes confirmed that Jarid2-GFP binds to Anf, Mlc2a, and Mhca promoters (Figure 3).

\section{Reductions of Jarid 2 and Mhca Expressions but Increases of Anf and Mlc2a Expressions With Mechanical Stress}

Expression of mRNA in stressed HL-2 cell layers was assessed by ratiometric RT-PCR. Mechanical stress induced a time-dependent reduction in Jarid2 expression but had

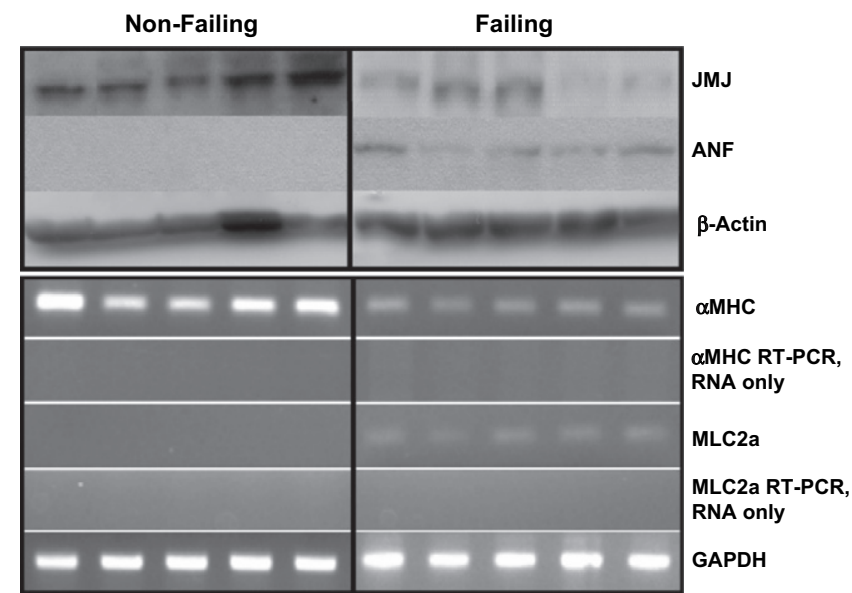

A
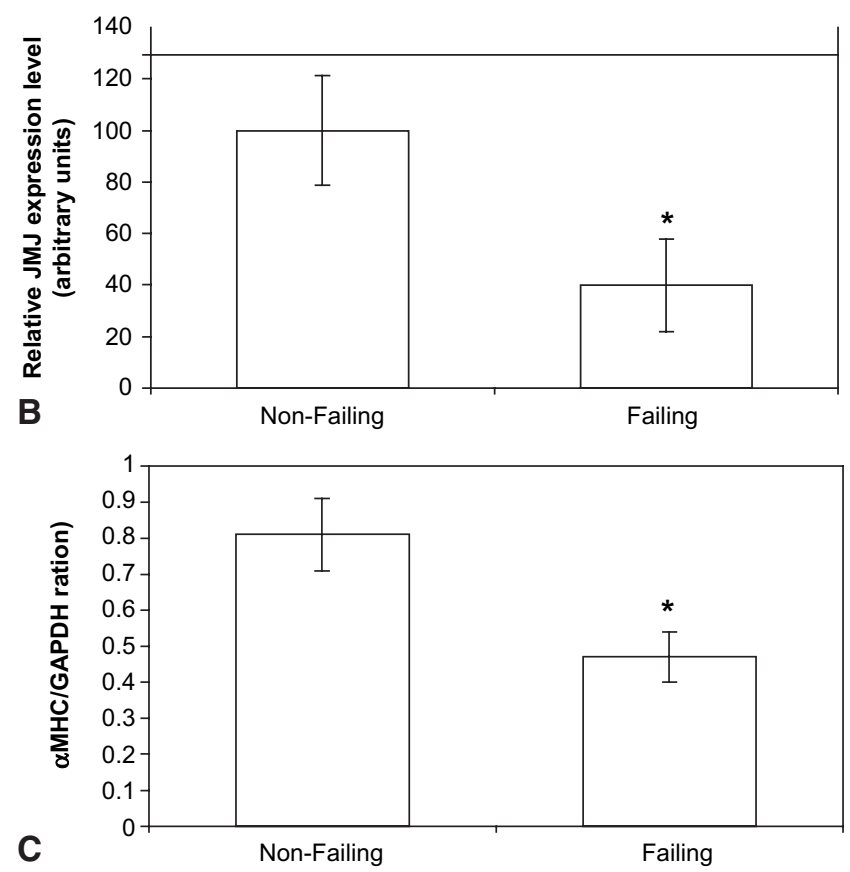

Figure 1. Jumonji (JARID2) levels are decreased in failing human ventricular biopsy samples. A, Representative Western blots (top panel) and reverse transcriptase-polymerase chain reaction (RT-PCR) gels (lower panel) from nonfailing and failing hearts. Jumonji protein expression is reduced in ventricular biopsy samples from failing hearts relative to nonfailing hearts; conversely, atrial natriuretic factor (ANF) is not detectable in nonfailing ventricles but is present in failing hearts. Reverse transcriptase-polymerase chain reaction for $\alpha$ myosin heavy chain ( $\alpha M H C$ ) messenger RNA shows decreased expression in failing hearts, whereas myosin light chain 2a (MLC2a) mesenger RNA is reexpressed in ventricular tissue from failing hearts. B, Western blot densitometry shows $60 \%$ decrease in Jumonji protein levels in failing relative to nonfailing hearts. Asterisk indicates $\boldsymbol{P}<.005$. C, Ratiometric reverse transcriptase-polymerase chain reaction shows $42 \%$ decrease in $\alpha$ myosin heavy chain messenger RNA expression in failing hearts. Asterisk indicates $P<$.005. GAPDH, Glyceraldehyde 3phosphate dehydrogenase. 


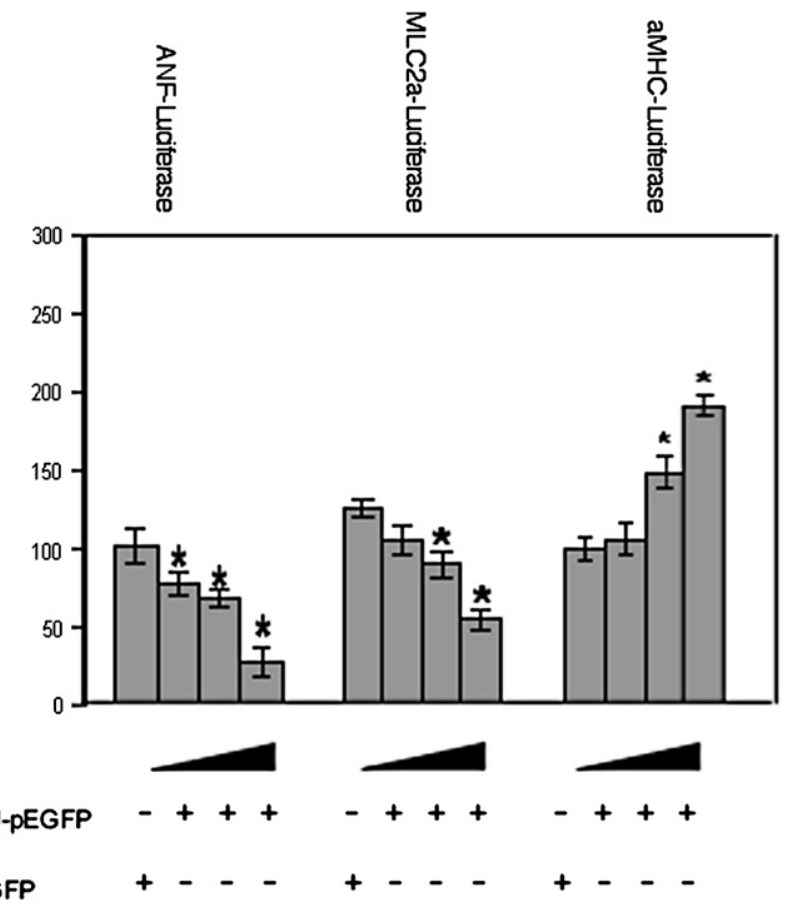

Figure 2. Murine gene Jarid2 mediates suppression of atrial natriuretic peptide (ANF) and myosin light chain 2a (MLC2a) gene transcription but promotion of $\alpha$ myosin heavy chain (aMHC) gene transcription. Control level of transcription of each promoter-luciferase construct in presence of $0.25 \mathrm{pmol}$ empty vector is set at 100, and other values are expressed relative to control. Increasing amounts of transfected plasmid from 0.1 to 0.25 pmol are denoted by black wedges. Jarid2 induces dose-dependent supression of ANF (left column) and MLC2a (central column) transcription but dose-dependent activation of $a M H C$ transcription (right column). Data shown represent at least three independent experiments, each performed in triplicate. Asterisk indicates $\boldsymbol{P}<.005$ versus control. pEGFP, Plasmid enhanced green fluorescent protein.

no effect on GAPDH (Figure 4, A): Jarid2 expression was decreased by $85 \%$ after 24 hours with mechanical stress relative to baseline $(P<.01$, Figure $4, B)$. Changes in Jarid2 expression were accompanied by increased ANF protein and $M L C 2 A$ mRNA levels and decreased $M H C A$ expression (Figure 4, A).

\section{Discussion}

We studied JARID2 expression in the failing human heart, in which altered ventricular $A N F, M L C 2 A$, and $M H C A$ expressions are well recognized. We also examined the interactions of Jarid2 with specific target promoters and other transcription factors in murine cell culture. In patients with aortic stenosis, we have shown the reexpression of a fetal gene program in cardiac myocytes subjected to increased afterload.

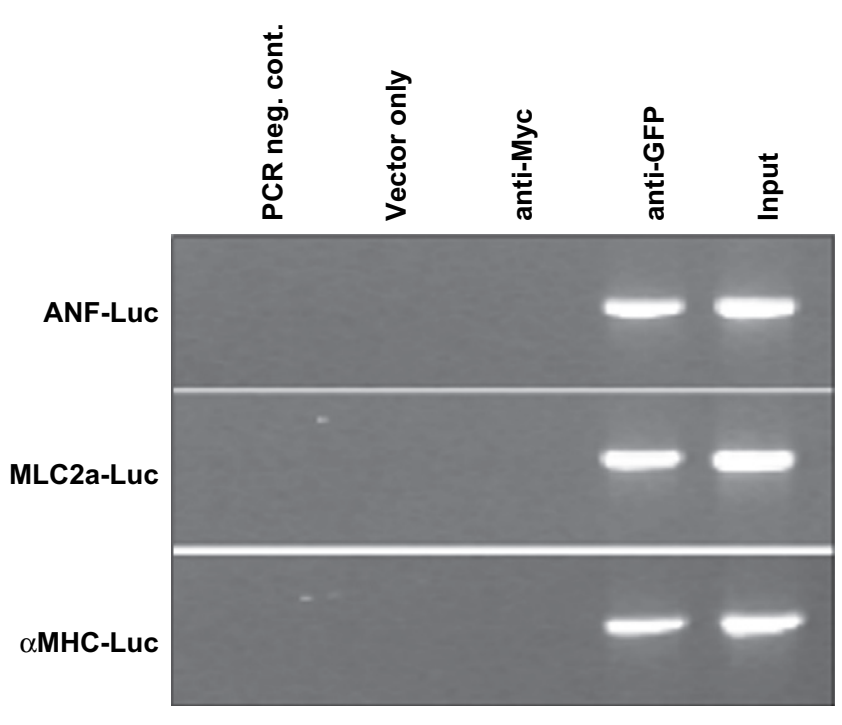

Figure 3. Coimmunoprecipitation of jmj-green fluorescent protein (GFP) complex with atrial natriuretic factor (ANF), myosin light chain 2a (MLC-2a), and $\alpha$ myosin heavy chain ( $\alpha M H C)$ promoters. An anti-green fluorescent protein antibody was used to precipitate jmj-promoter complexes formed by cotransfection of Jarid2-GFP, and target promoter-luciferase construct into HL-2 cells and polymerase chain reaction for luciferase (Luc) confirmed Jarid2-GFP binding to target promoter; target promoters are for atrial natriuretic factor, myosin light chain $2 \mathrm{a}$, and $\alpha$ myosin heavy chain. Negative controls (neg. cont.) are GFP plasmid vector only and irrelevant antibody (anti-Myc); cell lysates (Input) are used as positive controls.

Limitations of the Study

All patients with aortic stenosis have LV hypertrophy develop, so their myocardium cannot be considered normal even when ventricular function is preserved. As such, it may not be possible to extrapolate our findings to all cases of heart failure. For this clinical study, we selected patients in whom well-preserved LV function could clearly be differentiated from those with LV dilatation and heart failure in response to afterload.

\section{Regulation of MHCA Transcription by JARID2}

The protein $\alpha$-MHC has higher adenosine triphosphatase activity than does $\beta$-MHC and produces faster shortening velocity of cardiac myofibers. Lower ventricular systolic resistance and greater contractile force are observed in hearts with $\alpha$-MHC as the predominant myosin heavy chain isoform. $^{32,33}$. The $\alpha$-MHC levels are greatly reduced in failing hearts, regardless of etiology, and this has been proposed as an important factor for reduced myocardial contractility in heart failure. ${ }^{8,34}$ Several regulatory elements and their binding factors, including GATA4 and MEF2A, that promote cardiac expression of $M H C A$ have been identified, ${ }^{35}$ but molecular mechanisms underlying the suppression of 


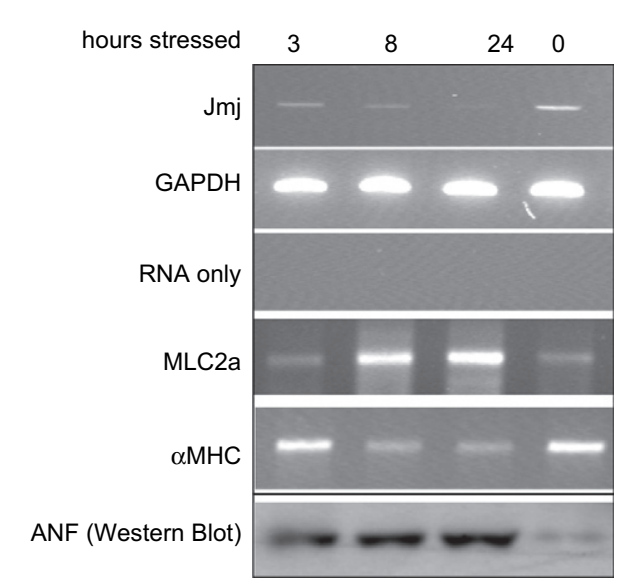

A

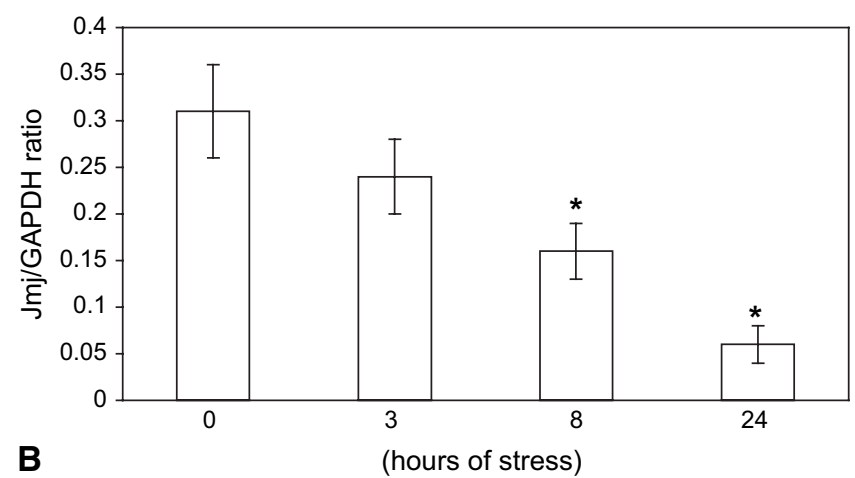

Figure 4. Gene Jarid2 is supressed by mechanical stress. A, reverse transcriptase-polymerase chain reactions for Jarid2, myosin light chain 2a (MLC2a), $\alpha$ myosin heavy chain $(\alpha M H C)$, and glyceraldehyde 3-phosphate dehydrogenase (GAPDH), with Western blotting for atrial natriuretic protein (ANF), were performed on extracts of HL-2 cells subjected to mechanical stress up to 24 hours. These gels show time-dependent reductions in Jarid2 and $\alpha$ myosin heavy chain messenger RNA expressions and time-dependent increases in myosin light chain 2a messenger RNA and atrial natriuretic factor protein expressions. B, Ratiometric reverse transciptase-polymerase chain reaction shows that Jarid2 expression decreases with longer duration of mechanical stress. Asterisk indicates $\boldsymbol{P}<.005$ relative to baseline (repeated measures analysis of variance).

MHCA expression in heart failure remain unknown. We have shown that JARID2 interacts with the MHCA promoter to activate $M H C A$ transcription in a dose-dependent manner. Our results differ from those of Kim and associates, ${ }^{18}$ who used a small promoter fragment (368 bp) to show transcriptional suppression by JARID2, whereas we used a much larger fragment $(>5 \mathrm{~kb})$. The suppression apparent on the minimal promoter may not be significant when a larger regulatory region is used. We also have shown that JARID2 expression is decreased in human heart failure, and this may contribute to the reduction in $\alpha$-MHC levels seen in failing hearts. This finding is compatibile with the reduced ventricular Mhca expression found in Jarid2 $2^{-1-}$ mice. ${ }^{22}$ Thus JARID2 has a role in the regulation of $M H C A$ gene expression.

\section{Regulation of MLC2A Transcription by JARID2}

The protein MLC-2a is seen throughout the fetal heart but is restricted to the atria in later development. ${ }^{36} M L C 2 A$ expression in the ventricular myocardium instead of $M L C 2 \mathrm{~V}$ produces a dilated cardiomyopathy characterized by impaired contractility and reduced ventricular ejection fraction. ${ }^{37} \mathrm{It}$ appears that the restriction of $M L C 2 A$ expression to the adult atrium is achieved through suppression of ventricular $M L C 2 A$ transcription. ${ }^{38}$ We have shown that JARID2 suppresses $M L C 2 A$ transcription, suggesting that JARID2 contributes to the normal mechanism for suppression of ventricular $M L C 2 A$ expression. We have also shown lowlevel $M L C 2 A$ expression in the ventricular myocardium of the failing hearts; this may be related to reduced jmj levels.

\section{Regulation of ANF Transcription by JARID2}

During fetal development, $A N F$ is expressed in both atria and ventricles, but it is restricted to the atria near birth. ${ }^{39}$ The minimal mammalian Anf promoter sufficient for correct chamber-specific expression in mice ${ }^{40}$ contains binding sites for $S R F, G A T A 4$, and Nkx-2.5 and was included in the construct used in this study. ANF expression is regulated by Nkx-2.5 and GATA4, and mutation of either binding site results in a failure of $A N F$ transcription. ${ }^{38}$ This finding is in agreement with those of previous studies with cultured cardiomyocytes, which showed that mutation of the NKE resulted in upregulation of $A N F$ promoter activity in ventricular cells. ${ }^{12}$ Small and $\mathrm{Kreig}^{38}$ interpreted these results as an indication that the GATA and NKE sites are recognition sequences for an unidentified suppressor of ventricular $A N F$ expression. Transgenic mice that overexpress myocardial Nkx-2.5 show persistent ventricular $A N F$ expression, ${ }^{41}$ suggesting that ventricular Nkx-2.5 competes with a putative suppressor factor. Studies of the $A N F$ promoter suggest that, as with $M L C 2 A$, atrial-restricted expression of $A N F$ is achieved through inhibition of ventricular expression. Our group and others ${ }^{16}$ have independently identified JARID2 as a suppressor of $A N F$ transcription. We have shown that a decrease in JARID2 levels, as found after mechanical stress and in human heart failure, is associated with increased $A N F$ expression. This observation, together with the finding that JARID2 associates with the $A N F$ promoter in vitro, strongly suggests that increased $A N F$ expression in failing hearts is at least partly the result of removal of suppression by declining JARID2.

\section{Regulation of Jarid2 Levels by Mechanical Stress}

Heart failure may follow hemodynamic overload. Myocytes are direct sensors of hemodynamic load that may be mimicked in vitro by subjecting cultured cell layers to mechanical stress. Murine HL-2 cells subjected to mechanical stress in 
vitro showed a striking and significant decrease $(85 \%)$ in Jarid2 levels. RT-PCR of stressed cell extracts showed increased Mlc2a and decreased Mhca expressions. Western blotting of parallel samples showed increased ANF in stressed cells. This is consistent with our observations that Jarid 2 suppresses Mlc2 $a$ and ANF expressions while activating Mhca expression, and it is also consistent with the upregulation of $A N F$ expression by mechanical stress.

\section{Decreased Jumonji Protein Expression in Failing Human Hearts}

JARID2 is a factor responsive to mechanical stress: this led us to examine JARID2 in pressure-overload induced heart failure. Immunoblot analysis showed decreased JARID2 protein product in LV biopsy samples from failing hearts relative to samples from nonfailing hearts with preserved LV function. These changes in protein level are consistent with those observed for mRNA in stressed cultured cells. We speculate that the stimuli for reduced JARID2 expression are chamber dilatation and increased wall stress, and reduced JARID2 expression in turn leads to misexpressions of $A N F, M L C 2 A$ and $M H C A$.

\section{Conclusions}

This study has demonstrated a previously unrecognized regulatory function of JARID2 with possible roles in regulating $A N F, M L C 2 A$, and MHCA genes in heart failure. We have shown that murine Jarid 2 expression is downregulated in response to mechanical stress and that this is associated with decreased Mhca expression but increased Mlc2a and Anf expressions. JARID2 is a crucial factor for the regulation of ANF, MLC-2a and $\alpha$-MHC proteins. Normal $A N F$ and $M L C 2 A$ expressions may be controlled by a balance among the actions of JARID2, GATA4, and Nkx-2.5; in the failing human heart, reduced JARID2 expression thus contributes to increased $A N F$ and $M L C 2 A$ expressions and to decreased $M H C A$ expression, which may ultimately contribute to the contractile insufficiency.

\section{Future Work}

It may be that the LV responds to increased afterload by reexpressing the fetal gene program. Our study suggests that this occurs at or after the point at which the LV begins to dilate, and that human JARID2 is an important transcriptional regulator central to the timing of this breaking point. This suggests we might perform JARID 2 characterization by endomyocardial biopsy during the assessment of the severity of aortic stenosis (while LV function remains well preserved). When JARID2 or cell cycle or fetal reprogramming genes are expressed, the cardiologist could argue that the time for aortic valve replacement has arrived. A panel of fetal reprogramming genes could be used to pinpoint the breaking point at which LV hypertrophy switches to LV dilatation. Genetic studies could thus be a useful clinical tool when recommending the timing of aortic valve replacement.
We now aim to study a full range of patients with aortic stenosis and regurgitation. We plan to use logistic regression analysis to further define the relationship between JARID2 and LVEF.

We thank Prof M. Nemer (Institut de Recherches Cliniques de Montréal, Montréal, Quebec, Canada), Dr J. Gulick and Prof J. Robbins (The Cleveland Clinic, Cleveland, Ohio), and Prof G. Lyons and Dr Y. Lee (University of Wisconsin School of Medicine and Public Health, Madison, Wis) for their kind gift of plasmids.

\section{References}

1. Katz AM. Heart failure: a hemodynamic disorder complicated by maladaptive proliferative responses. J Cell Mol Med. 2003;7:1-10.

2. Swynghedauw B. Molecular mechanisms of myocardial remodeling. Physiol Rev. 1999;79:215-62.

3. Chien KR, Knowlton KU, Zhu H, Chien S. Regulation of cardiac gene expression during myocardial growth and hypertrophy: molecular studies of an adaptive physiologic response. FASEB J. 1991;5:3037-46.

4. Vesely DL. Atrial natriuretic peptides in pathophysiological diseases. Cardiovasc Res. 2001;51:647-58.

5. Drexler H, Hanze J, Finckh M, Lu W, Just H, Lang RE. Atrial natriuretic peptide in a rat model of cardiac failure. Atrial and ventricular mRNA, atrial content, plasma levels, and effect of volume loading. Circulation. 1989;79:620-33.

6. Sugawara A, Nakao K, Morii N, Yamada T, Itoh H, Shiono S, et al. Synthesis of atrial natriuretic polypeptide in human failing hearts. Evidence for altered processing of atrial natriuretic polypeptide precursor and augmented synthesis of $\beta$-human ANP. J Clin Invest. 1988;81:1962-70.

7. Tsuchimochi H, Kurimoto F, Ieki K, Koyama H, Takaku F, Kawana M, et al. Atrial natriuretic peptide distribution in fetal and failed adult human hearts. Circulation. 1988;78:920-7.

8. Nakao K, Minobe W, Roden R, Bristow MR, Leinwand LA. Myosin heavy chain gene expression in human heart failure. J Clin Invest. 1997; 100:2362-70.

9. Lowes BD, Minobe W, Abraham WT, Rizeq MN, Bohlmeyer TJ, Quaife RA, et al. Changes in gene expression in the intact human heart. Downregulation of $\alpha$-myosin heavy chain in hypertrophied, failing ventricular myocardium. J Clin Invest. 1997;100:2315-24.

10. Walsh R, Henkel R, Robbins J. Cardiac myosin heavy- and light-chain gene expression in hypertrophy and heart disease. Heart Failure. 1991; 6:238-43.

11. Morin S, Charron F, Robitaille L, Nemer M. GATA-dependent recruitment of MEF2 proteins to target promoters. EMBO J. 2000;19:2046-55.

12. Durocher D, Chen CY, Ardati A, Schwartz RJ, Nemer M. The atrial natriuretic factor promoter is a downstream target for Nkx-2.5 in the myocardium. Mol Cell Biol. 1996;16:4648-55.

13. Fattaey AR, Helin K, Dembski MS, Dyson N, Harlow E, Vuocolo GA, et al. Characterization of the retinoblastoma binding proteins RBP1 and RBP2. Oncogene. 1993;8:3149-56.

14. Gregory SL, Kortschak RD, Kalionis B, Saint R. Characterization of the dead ringer gene identifies a novel, highly conserved family of sequencespecific DNA-binding proteins. Mol Cell Biol. 1996;16:792-9.

15. Peterson CL, Herskowitz I. Characterization of the yeast SWI1, SWI2, and $S W I 3$ genes, which encode a global activator of transcription. Cell. 1992;68:573-83.

16. Kim TG, Chen J, Sadoshima J, Lee Y. Jumonji represses atrial natriuretic factor gene expression by inhibiting transcriptional activities of cardiac transcription factors. Mol Cell Biol. 2004;24:10151-60.

17. Kim TG, Kraus JC, Chen J, Lee Y. JUMONJI, a critical factor for cardiac development, functions as a transcriptional repressor. J Biol Chem. 2003;278:42247-55.

18. Kim TG, Jung J, Mysliwiec MR, Kang S, Lee Y. Jumonji represses $\alpha$ cardiac myosin heavy chain expression via inhibiting $M E F 2$ activity. Biochem Biophys Res Commun. 2005;329:544-53.

19. Toyoda M, Shirato H, Nakajima K, Kojima M, Takahashi M, Kubota M, et al. jumonji downregulates cardiac cell proliferation by repressing cyclin D1 expression. Dev Cell. 2003;5:85-97. 
20. Ohno T, Nakajima K, Kojima M, Toyoda M, Takeuchi T. Modifiers of the jumonji mutation downregulate cyclin D1 expression and cardiac cell proliferation. Biochem Biophys Res Commun. 2004;317:925-9.

21. Takahashi M, Kojima M, Nakajima K, Suzuki-Migishima R, Takeuchi T. Functions of a jumonji-cyclin D1 pathway in the coordination of cell cycle exit and migration during neurogenesis in the mouse hindbrain. Dev Biol. 2007;303:549-60.

22. Lee Y, Song AJ, Baker R, Micales B, Conway SJ, Lyons GE. Jumonji, a nuclear protein that is necessary for normal heart development. Circ Res. 2000;86:932-8.

23. Takeuchi T, Kojima M, Nakajima K, Kondo S. jumonji gene is essential for the neurulation and cardiac development of mouse embryos with a C3H/He background. Mech Dev. 1999;86:29-38.

24. Argentin S, Ardati A, Tremblay S, Lihrmann I, Robitaille L, Drouin J, et al. Developmental stage-specific regulation of atrial natriuretic factor gene transcription in cardiac cells. Mol Cell Biol. 1994; 14:777-90.

25. Lyons GE. In situ analysis of the cardiac muscle gene program during embryogenesis. Trends Cardiovasc Med. 1994;4:70-7.

26. Sahn DJ, DeMaria A, Kisslo J, Weyman A. Recommendations regarding quantitation in M-mode echocardiography: results of a survey of echocardiographic measurements. Circulation. 1978;58:1072-83.

27. Kemp TJ, Sadusky TJ, Simon M, Brown R, Eastwood M, Sassoon DA, et al. Identification of a novel stretch-responsive skeletal muscle gene (Smpx). Genomics. 2001;72:260-71.

28. Doevendans PA, Bronsaer R, Lozano PR, Kubalak S, van Bilsen M. The murine atrial myosin light chain-2 gene: a member of an evolutionarily conserved family of contractile proteins. Cytogenet Cell Genet. 2000;90: 248-52.

29. Gulick J, Hewett TE, Klevitsky R, Buck SH, Moss RL, Robbins J. Transgenic remodeling of the regulatory myosin light chains in the mammalian heart. Circ Res. 1997;80:655-64.

30. Wu WS, Vallian S, Seto E, Yang WM, Edmondson D, Roth S, et al. The growth suppressor $P M L$ represses transcription by functionally and physically interacting with histone deacetylases. Mol Cell Biol. 2001; 21:2259-68.
31. Claycomb WC, Lanson NA Jr, Stallworth BS, Egeland DB, Delcarpio JB, Bahinski A, et al. HL-1 cells: a cardiac muscle cell line that contracts and retains phenotypic characteristics of the adult cardiomyocyte. Proc Natl Acad Sci U S A. 1998;95:2979-84.

32. Shroff SG, Motz W. Left ventricular systolic resistance in rats with hypertension and hypertrophy. Am J Physiol. 1989;257(2 Pt 2): H386-94.

33. Shroff SG, Naegelen D, Clark WA. Relation between left ventricular systolic resistance and contractile rate processes. Am J Physiol. 1990; 258(2 Pt 2):H381-94.

34. Miyata S, Minobe W, Bristow MR, Leinwand LA. Myosin heavy chain isoform expression in the failing and nonfailing human heart. Circ Res. 2000;86:386-90.

35. Molkentin JD, Kalvakolanu DV, Markham BE. Transcription factor GATA-4 regulates cardiac muscle-specific expression of the $\alpha$-myosin heavy-chain gene. Mol Cell Biol. 1994;14:4947-57.

36. Kubalak SW, Miller-Hance WC, O'Brien TX, Dyson E, Chien KR. Chamber specification of atrial myosin light chain-2 expression precedes septation during murine cardiogenesis. J Biol Chem. 1994;269:16961-70.

37. Chen J, Kubalak SW, Minamisawa S, Price RL, Becker KD, Hickey R, et al. Selective requirement of myosin light chain $2 \mathrm{v}$ in embryonic heart function. J Biol Chem. 1998;273:1252-6.

38. Small EM, Krieg PA. Molecular regulation of cardiac chamber-specific gene expression. Trends Cardiovasc Med. 2004;14:13-8.

39. Zeller R, Bloch KD, Williams BS, Arceci RJ, Seidman CE. Localized expression of the atrial natriuretic factor gene during cardiac embryogenesis. Genes Dev. 1987;1:693-8.

40. Knowlton KU, Rockman HA, Itani M, Vovan A, Seidman CE, Chien KR. Divergent pathways mediate the induction of ANF transgenes in neonatal and hypertrophic ventricular myocardium. J Clin Invest. 1995;96:1311-8.

41. Takimoto E, Mizuno T, Terasaki F, Shimoyama M, Honda H, Shiojima I, et al. Up-regulation of natriuretic peptides in the ventricle of Csx/Nkx2-5 transgenic mice. Biochem Biophys Res Commun. 2000;270:1074-9. 